\title{
Mi comienzo como enfermero. Una narración personal
}

\author{
My beginning as a nurse. A personal narrative \\ Meu começo como enfermeiro. Uma narração pessoal
}

\author{
Cristo Manuel Marrero González ${ }^{1}$ \\ ${ }^{1}$ Enfermero en el Servicio Canario de la salud. Área de salud de Tenerife \\ (España). Doctor por la Universidad de La Laguna (España) Correo \\ electrónico: cmmarrerogonzalez@gmail.com \\ Cómo citar este artículo en edición digital: Marrero González, C. (2019). Mi comienzo como enfermero. \\ Una narración personal. Cultura de los Cuidados (Edición digital), 23 (54). Recuperado de \\ http://dx.doi.org/10.14198/cuid.2019.54.04 \\ Correspondencia: Calle Infante Juan Manuel 16, 38010. Santa Cruz de Tenerife. Tenerife. España. Tel: \\ $(+34$ 696134384) \\ Correo electrónico de contacto: cmmarrerogonzalez@gmail.com \\ Recibido: 11/12/2018; Aceptado: 20/03/2019
}

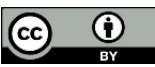

\begin{abstract}
In this document, I intend to narrate my main experiences in a brief and personal way when I started to work as a nurse in a hospital in Tenerife (Spain). These events happened in the second half of 2009. I reflect on the experience and I also try to argue my experiences based on the knowledge that I have acquired by developing a phenomenological doctoral thesis in which I study this event with nurses who begin to work in different health institutions in Tenerife.
\end{abstract}

Keywords: Novice nurse, personal narrative, phenomenology.

\section{RESUMO}

Neste documento, pretendo narrar minhas principais experiências de forma breve e pessoal quando comecei a trabalhar como enfermeiro em um hospital em Tenerife (Espanha). Estes eventos aconteceram no segundo semestre de 2009. Refiro sobre a experiência e também tento discutir minhas experiências com base no conhecimento adquirido através do desenvolvimento de uma tese de doutorado fenomenológico no qual estudo este evento com enfermeiras que começam a trabalhar em diferentes instituições de saúde em Tenerife.

Palavras chave: Doença de Alzheimer, cuidadores familiares, experiências, adaptação, experiências.

\section{RESUMEN}

Con el presente manuscrito tan solo pretendo narrar de una forma breve $y$ personal mis principales vivencias al comenzar a trabajar como enfermero en un hospital de Tenerife (España). Esto aconteció en el segundo semestre de 2009. Reflexiono sobre lo vivido y además intento argumentar mis vivencias apoyándome en los conocimientos que he adquirido elaborando una tesis doctoral fenomenológica en la que estudio este acontecimiento con enfermeras que comienzan a trabajar en diferentes 
instituciones sanitarias de Tenerife.

Palabras clave: Enfermera novel, narración personal, fenomenología.

\section{INTRODUCCIÓN}

La revista Cultura de los Cuidados ofrece la posibilidad de que muchos autores podamos producir y publicar trabajos de corte fenomenológico y/o narrativo. Hasta ahora, había producido de forma muy rigurosa y metodológica todo aquello relacionado con las vivencias de la incorporación laboral de las enfermeras en la isla de Tenerife (España) apoyándome en autoras "clásicas" dentro de la enfermería como son Kramer (1974) o Benner (1987) y en otros muchos trabajos a nivel internacional que han seguido sus pasos hasta nuestros días. De hecho, con mi tesis doctoral (Marrero, 2017) he intentado argumentar y poner nombre a esos fenómenos o hechos que describen las enfermeras al comenzar a trabajar en esta noble profesión. Seguramente la profesión más bella que haya conocido la humanidad, desde sus inicios.

Pero en ninguna de esas publicaciones o trabajos he podido mencionar o explicar realmente la motivación de ese trabajo. Tengo que reconocer que para mí nunca ha sido sencillo hablar abiertamente de este tema. Ni siquiera aún hoy con una posible madurez personal y profesional consolidada. Creo que tras casi diez años de profesión (egresé de la Universidad de La Laguna en el año 2009) veo conveniente manifestar mi propia vivencia a mi incorporación laboral. Hasta ahora había recogido los testimonios de los demás para tratar de interpretar a través de los mismos, cómo es el paso de estudiante a profesional (Marrero y García, 2017) y todo lo que siente la nueva enfermera dentro del contexto laboral de la realidad española.

En síntesis, el objetivo de este manuscrito es manifestar mi propia vivencia en el paso de estudiante a profesional y todo lo que sentí en los primeros meses como profesional. Las vivencias las narraré expresándolas sobre este documento, evocando yo mismo mis propias vivencias sin el apoyo de documentos o elementos externos que trasladen mi mente a aquella época. Sin embargo, dado el "sesgo" que presento por haber estudiado este tema, nombraré algún concepto que lo referenciaré con citas bibliográficas.

\section{Contexto personal y laboral}

Corría junio de 2009. Los últimos exámenes y las últimas prácticas clínicas de tercero de enfermería. Hay que decir que pertenezco a una de las últimas promociones de diplomado en enfermería en España. Estaba contento porque había superado las prácticas y los últimos exámenes. Especialmente los de médicoquirúrgica que eran densos y largos. La nota media la asignatura no superaba yo creo que el 6,5. Yo he de decir que nunca fui un estudiante de "matrícula", pero llegué a darme cuenta de que eso era lo de menos. Aún hoy me reafirmo en lo mismo. Cabe mencionar que esta profesión en la isla de Tenerife hasta mi año de graduación (2009), tenía una salida laboral demasiado inminente. Era sacar el justificante de pago de las tasas del título y ponerte a trabajar. No exagero.

Recuerdo los días posteriores a haberse publicado las primeras actas de junio. Bien pues el 29 de junio de 2009 que era lunes y que en la semana anterior se habían publicado las actas ese mismo día toda mi promoción, casi toda, se había levantado ese 
día con una motivación e ilusión por poder trabajar. Yo no. No es que no quisiera trabajar. Es que tenía miedo. Se me notaba en la cara: no estaba feliz. Sabía que no iba a ser fácil. En honor a la verdad yo estaba anticipando el llamado "choque con la realidad" que describía Kramer (1974) en que la realidad iba a ser distinta a cómo es la profesión descrita en la literatura. Además de que no me sentía preparado para entrar en un contexto tan complejo como es el de un hospital de tercer nivel. Yo describo en los resultados de mi tesis que muchas enfermeras sienten ya un choque desde la propia carrera durante las prácticas clínicas porque ya observan y aprenden cómo es la realidad, la responsabilidad, los ambientes de trabajo... Pues bien, dada mi personalidad ese choque se me multiplicaba. Era sin duda un salto inesperado al fondo de una piscina (Duchsher, 2009).

El miedo me hacía sentir ansiedad y la ansiedad me deprimía. Hago memoria y una gran amiga mía de promoción percibió dicho miedo o angustia y me dijo con cara de pena y empatía mirándome a mis ojos rayados:

-No quieres trabajar...

Y así era. Me sentía un bicho raro: ¿cómo era posible estar triste por tener oportunidades laborales inminentes? ¿Cómo era posible estar así en un contexto donde la crisis económica se cebaba con España con un paro que cada vez iba a peor? Claro, yo estos sentimientos no los contaba bien por miedo a juzgarme, por vergüenza... Pero me desahogaba llorando en privado. No, no me avergüenzo de reconocer que lloro. Soy humano.

Saqué el papel de la secretaría de la escuela. En el mismo día, entrevista de trabajo en el hospital de tercer nivel. Tres preguntas banales. Aquello no parecía una entrevista de trabajo, sino un examen psicotécnico. Las normas de contratación eran claras: contrato que se ofrezca, contrato que tienes que coger. Si no, te echan de la lista o bolsa de contratación. Da igual si el primer contrato es para trabajar en una planta comenzando de noche en un turno en el que estés solo/a o que vayas a un servicio de alta complejidad como es una unidad de críticos sin programa de orientación (Saghafi 2014; Marrero y García, 2017) aquí se trata de la aventura y de tratar al personal de forma fácilmente intercambiable (Pera i Fàbregas, 1998; Lleixá Fortuño et al. 2010). Pedía información y asesoramiento, pero era en balde: soy yo el que tenía que ponerse las pilas. Dejarme de tonterías, espabilar y buscar información en internet... Hoy recuerdo esto y se me ponen los pelos de punta. Sobre todo, teniendo en cuenta la argumentación que he ido dando en los diferentes trabajos.

\section{Entrada al contexto laboral}

A los pocos días, un 7 de julio, soy llamado para comenzar a trabajar en la unidad de críticos de dicho hospital. La concepción de la contratación de las enfermeras en España se hace de forma indiscriminada: las enfermeras sirven para todo, da igual que sea novata o que no haya hecho o haya adquirido experiencia en determinados contextos. Las enfermeras son multiusos. Son "máquinas" para sacar trabajo adelante a las que se les exige la máxima eficacia y eficiencia, además de responsabilidad. Si tienen oportunidad, lean el Artesano de Richard Sennett (2009). Evidentemente yo estaba muerto de miedo. Hoy lo veo con perspectiva y digo, ¿cómo no iba a tener miedo? En prácticas de tercero tenía nociones limitadas de tratar a un paciente crítico. Era un profesional muy limitado. La 
UCI evidentemente era muy abstracta para mí... Benner (1987), claro que me daría la razón. Todo hay que decirlo, entras a dicho servicio ya como profesional al que se le exige la máxima responsabilidad como al que lleva 10 años allí.

Fue un contrato de una semana. Durante ese tiempo me volví loco buscando información, consultando. Me sentía una carga para mis compañeros/as. Algunas enfermeras empatizaban conmigo, yo lo agradecía. Otras en cambio me decían y me reprochaban mi limitación, y que las sobrecargara. Y lo digo: tenían razón. Había que aprender rápido. Había que ser eficiente y eficaz... Buen profesional. Yo era muy torpe. Les pido perdón si me leen ahora y reconocen quién soy. Pero es que existe un conflicto: según Benner (1987), yo en un par de semanas no podía asumir todos esos atributos de situación de un paciente tan complejo como es un crítico. En mi tesis, dentro del marco teórico, podrán consultar algunos trabajos de las vivencias de las enfermeras noveles en críticos en diferentes países y culturas. Luego también ocurría la hipocresía de recriminarte que no te volvieras loco por aprender rápido, pero la realidad es que se exige lo máximo. En algunos casos se daba el llamado Eating Our Young (Meissner, 1986). Ese canibalismo que se da dentro de los contextos laborales, y más aún se da con una novata. Hay veces que las malas formas pueden deberse a la sobrecarga de trabajo que supone estar pendiente de la novata (siempre tengo la costumbre de utilizar enfermera como concepto generalizador. Esta es una profesión que las mujeres han sacado adelante y no se les ha sabido valorar lo suficiente), bien porque te has aculturizado (Harris, 1990) tanto en el contexto de trabajo que ves al de fuera, al nuevo/a, como un blanco fácil de críticas y burlas... Porque no llega a tu nivel, porque no reparte el carro de medicación más rápido que tú...

Los siguientes meses fueron igual de duros: más contratos como uno en neonatología y "plantilla volante" ya prácticamente desde agosto hasta noviembre. El temor al error, la vivencia de la responsabilidad era un gran peso para mí. No voy a exagerar cuando digo que para mí trabajar suponía una auténtica supervivencia (Newton y Mackenna, 2007). ¿Por qué era una supervivencia? La plantilla volante que en otras instituciones sanitarias se llama "recursos humanos", "suplencias", "refuerzo"... Es un equipo de enfermería que rota constantemente. Cada enfermera de dicho servicio no tiene una ubicación concreta o fija. La enfermera sirve para todo: desde auxiliar en una consulta a un especialista, a trabajar en una planta, en quirófano o en una unidad de críticos. Bien yo cada día vivía en una incertidumbre. Pocas veces iba de refuerzo a esos lugares. Yo iba a suplir la ausencia de una enfermera en determinados sitios, asumiendo la responsabilidad de un determinado lugar y de unos de determinados pacientes, aunque desconociera el servicio. Recuerden: ser eficiente, eficaz y ser Macgyver. Solo que desgraciadamente esto no era una ficción, sino una realidad.

Roté y roté por todo ese hospital. Vivía un doble choque con la realidad: ser un novato cagado de miedo y a la vez tener que adaptarme a las culturas de cada unidad (Kelly y Ahren, 2008). Cada día al ir a trabajar era una capacidad de resiliencia increíble. Era un ataque de ansiedad al acudir a mis superiores a que me derivasen a trabajar a un lugar ya fuera una planta o a un servicio especial. Había superiores más empáticos en que te preguntaban a dónde querías ir, cuáles eran tus preferencias o dónde te veías mejor trabajando. Otro no. Te 
decían: "UVI". Era asumirlo e ir a dar lo mejor de ti con la buena fe posible. Y más. Con ganas de aprender, de colaborar y de superarte, pero para algunas enfermeras eso no era suficiente. De tantos y tantos días que repetía un determinado lugar, era recibido con malas caras y recriminaciones... Porque había vuelto loco a todo el mundo, porque digamos que sus argumentos se basaban en que era un incompetente. ¡Por Dios que mi nivel de principiante básico no daba para más! (Benner, 1987; Alfaro-LeFevre, 2009). Tanto que se habla de humanizar los cuidados y no somos humanos ni con nosotros mismos.

En una profesión tan bella que se tenga que sufrir tanto por un contexto, por un medio (Marrero, 2017). Deberíamos reflexionar sobre nuestra imagen como profesión y sobre nuestras creencias y actos (Fernández, 2017).

Para no extenderme demasiado he de decir que había días muy buenos. Si mis compañeros/as me apoyaban y me potenciaban yo era feliz, disfrutaba. Pero esos días fueron escasos con respecto a los malos. La balanza estaba desequilibrada.

Hasta que llegó un 21 de noviembre de 2009 y mi cuerpo, mi alma y mi resiliencia ya no daban para más. Estaba débil físicamente, estaba muy asustado y estaba empezando con una depresión. En ese mes sufrí una falta de respeto de una anestesióloga mientras recibía $y$ monitorizaba a una paciente procedente de un quirófano a URPA, Me faltaba de apoyo de por parte de algunas compañeras, falta de realización personal... Total que mi médico tuvo que darme la incapacidad temporal. Reflexioné mucho durante el tiempo de convalecencia y de descanso. Pasé la navidad en familia y alejado de todo. Y tomé la decisión de rescindir el contrato con dicho hospital. En un contexto socioeconómico nada sencillo con la crisis económica en pleno auge.

En el 2010 comencé a trabajar en atención primaria y me adapté mucho mejor a los entornos de trabajo. Con sus pros y contras, me he sentido realizado. He evolucionado profesionalmente hasta el punto ya incluso de convertirme en doctor de esta bellísima profesión, de ser investigador y de ayudar a contribuir al pensamiento de esta ciencia.

Guardo también buenos recuerdos de mi paso como estudiante y como profesional novel de hospital de que hablo. Tal es así, que estoy muy agradecido por la atención que recibió un ser querido hace pocos meses en una circunstancia de salud grave. No quiere decir que a todo el mundo le vaya mal en un determinado sitio: las vivencias y percepciones definen cómo nos adaptamos a diferentes lugares. Creo que, en un medio sociológicamente similar han de existir muchas diferencias psicológicas. Seguramente mi personalidad, mis características, no se amoldaban a la cultura de esa institución. Cada ser humano es distinto y lo que para muchos puede ser bueno, para otros no lo es. Y es así. La vida es así. De ahí la importancia de la fenomenología como enfoque de estudio en la enfermería.

Solo espero que el mundo académico, el institucional, el sindical y el colegial, aúnen fuerzas para mejorar nuestra incorporación laboral (Marrero, 2017; Marrero y García, 2017). Apelo a la libertad de pensamiento para así poder luchar por mejorar lo que ocurre en este país con esta excelente profesión. Me he desahogado, y he sentido que he roto ese nudo que durante mucho tiempo llevaba dentro. Es el paso de los años lo que hace liberarte.

"Antes de correr, hay que aprender a caminar" 


\section{BIBLIOGRAFÍA}

- Alfaro-LeFevre, R. (2009). Pensamiento crítico y juicio clínico en enfermería: un enfoque práctico para un pensamiento centrado en los resultados. (4. ${ }^{\mathrm{a}}$ ed.). Elsevier Masson.

- Benner, P. (1987). Práctica progresiva en enfermería: Manual de comportamiento profesional. (1. ${ }^{\mathrm{a}}$ ed.). Barcelona: Enfermería y sociedad. Ediciones Grijalbo, S. A.

- Duchscher, J. E. B. (2009). Transition shock: the initial stage of role adaptation for newly graduated Registered Nurses. Journal of advanced nursing, 65(5), 1103-1113.

- Fernández, D. Á. (2017). Por qué su imagen profesional puede afectar seriamente a la salud de las personas que atiende (y a la suya propia). Ene, Revista de Enfermería, 11(2).

- Harris, M. (1990). Antropología Cultural. Madrid: Alianza Editorial.

- Kelly, J., y Ahern, K. (2008). Preparing nurses for practice a phenomenological study of the new graduate in Australia. Journal of Clinical Nursing, 18(6), 910-918.

- Kramer, M. (1974). Reality shock: Why nurses leave nursing. St. Louis: Mosby.

- Lleixá Fortuño M, Gisbert Cervera M, Marques Molias L, Albacar Rioboo N, Monteso Curto P y Ferre Grau C. (2010). Experiencia de inserción laboral de los profesionales de Enfermería noveles. Metas de Enfermería, 13(4), 64-69.

- Marrero, C. M. (2017). Estudio fenomenológico de la experiencia de incorporación al contexto laboral de enfermeras egresadas de la Universidad de La Laguna entre 2009 y 2014 (Tesis doctoral). Universidad de La Laguna. España.

- Marrero, C. M., y García, A. M. (2017). La vivencia del paso de estudiante a profesional en enfermeras de Tenerife (España). Un estudio fenomenológico. Ene, Revista de Enfermería, 11(1).

- Marrero, C. M., y García A. M. (2017). Narraciones pertenecientes a enfermeras egresadas de la Universidad de La Laguna sobre cómo mejorar su incorporación al mundo laboral en Tenerife. Ene, Revista de Enfermería, 11(2).

- Meissner, J. E. (1986). Nurses: Are we eating our young? Nursing, 16(3), 51-53.

- Newton, J. M., y McKenna, L. (2007). The transitional journey through the graduate year. A focus group study. International journal of nursing studies, 44(7), 1231-1237.

- Pera i Fàbregas, I. (1998). La solitud del debutant. Infermeria de Barcelona, 14 (2).

- Saghafi, F. (2014). The journey from new graduate to proficient nurse in the Intensive Care Unit: A descriptive phenomenological study (Doctoral dissertation). Australian Catholic University.

- Sennett, R. (2009). El artesano. Barcelona: Ed. Anagrama. 